\title{
STAR-VITAL project: Factors for ensuring participation in health promotion programs
}

\author{
Natalija Rozman', Klemen Širok ${ }^{2}$ \\ I National Institute of Public Health, Trubarjeva 2, 1000 Ljubljana, Slovenia \\ ${ }^{2}$ University of Primorska, Faculty of Health Sciences, Polje 42, 6310 Izola, Slovenia \\ natalija.rozman@nijz.si; klemen.sirok@fvz.upr.si
}

\section{Abstract}

Introduction: To ensure sustainable and healthy jobs, the STARVITAL project encourages stakeholders to tackle the challenges of an aging workforce. Free of charge, we carry out individualized workplace wellbeing activities for employees and managers in companies. Participants are - in addition to other measures such as workshops, mentoring and coaching - also admitted into customized communication campaigns based on customer relations management (CRM) information platform, with aim to change their health related behaviour. This approach (with the internal name ePlatform), which is presented below, primarily addresses the general challenge of low levels of participation or active involvement of employees in workplace wellbeing programs. Methods: CRM systems are used to manage interactions with current and potential customers, using analysis of customer interaction history with a business to improve customer relationship with a focus on customer retention and encourage purchasing behaviour. The CRM based ePlatform enables advanced personalized web-based and mobile device communication, mobile surveying, GDPR form management, API data sharing, advanced user segmentation, and advanced monitoring and users' interests' statistics. The wealth of data generated by ePlatform also enables identification of factors related to the intensity of employee and company involvement in workplace wellbeing measures: work specifics, exposure to health risk factors, current lifestyle, company specifics, industry specifics, employee's health issues, demographic characteristics. Results: As the project runs in several waves, we present the results of the first group of 31 (out of 80 ) companies, which are represented by 74 managers, involved in the campaign. The campaign for management consists of nine activities, aimed at the development and successful implementation of a workplace wellbeing program. The use of the ePlatform so far 
shows a $68 \%$ success rate ( 21 out of 31 companies are currently actively participating). With the help of analysis of variance, in the coming months we will identify those differences between individuals and companies that are related to the intensity of participation in campaigns and the implementation of planned activities. Discussion and conclusions: Proper use of ePlatform enables improved support and empowerment of workers and companies in changing workplace and behaviours, leading to improved care for their own health and prolongation of work activity. To maximize the impact, it is necessary to identify approaches, activities and/or factors that motivate those involved to participate and to change their health and wellbeing behaviour.

\section{Keywords: responsiveness, participation, CRM, measures, health promotion}

\section{Introduction}

Despite numerous guidelines, strategies, projects, platforms and measures in the field of workplace wellbeing, challenge remains how to awaken the interests of both workers and companies, as these measures do not bring immediate health or financial benefits. The reasons for this are multifaceted and reach both at the level of the employee (lack of interest, ignorance, poor relationship with the employer, ...), companies (inadequate organizational culture, values of management, absence of age management, ...), narrower and wider social environment (social values, prevailing lifestyles and habits) and regulatory framework (absence of subsidies or tax incentives supporting workplace wellbeing) (Bal et al., 2011; Loeppke et al., 2013; WHO, 2020). In the STAR-VITAL project, we are aware of the need to develop new approaches and systems for more effective take-up and retention of employees in health promotion programs and healthy workplace measures, which are ultimately aimed at retaining an aging workforce.

In the STAR - VITAL project (https://www.star-vital.si/o-projektu) we help companies free of charge in establishing, adapting and integrating concrete measures to protect and promote the health and wellbeing of employees in order to ensure sustainable and healthy workplaces - especially for older employees (45+). Project activities are designed to enable an individualized application of measures and identification and awakening of the interests of both employees and managers. An important measure within the project is the ePlatform, which works through the internet or e-mail and is adapted for the use on mobile devices. ePlatform is an innovative approach to promote and monitor the introduction of workplace wellbeing programmes for workers and companies' management in the fields of ergonomics and movement, stress, communication, nutrition, managerial practices, sleep, absenteeism presentism and age management (STAR-VITAL, 2020). 
The purpose of this paper is to present the solution for more effective promotion of employee participation in workplace wellbeing programs by using appropriate IT solutions (ePlatform). We also present the factors that encourage or inhibit the participation and willingness of employees to change their behaviours, related to ensuring health at work.

\section{Methods}

The ePlatform is based on a CRM (customer relationship management) solution, which basically enables a modern marketing approach for communicating and influencing purchase related behaviour. CRM is the strongest and the most efficient approach in maintaining and creating relationships with customers (Juneja, 2020). If many previous approaches and measures implemented in Slovenia are based on pull approach, where the offered content passively waits for the potential interest of customers (e.g. Zrno zdravja, Čili za delo, ASI...), the ePlatform on the other hand additionally brings a push approach, in which employees segmented according to their identified needs are being actively persuaded, stimulated and encouraged with tailored communication campaigns to change their behaviour (ePrvak d.o.o., 2020).

The ePlatform enables: advanced personalized communication through the internet and mobile devices, surveying via mobile devices, management of GDPR forms, API data exchange, advanced user segmentation and advanced statistics for monitoring communication and user interests. The wealth of data generated by the ePlatform also enables the identification of determinants related to the intensity of workers' and companies' involvement in workplace wellbeing measures: nature of work, exposure to health risk factors, current lifestyle, company specifics, industry specifics, presence health problems, demographic characteristics, etc.

\section{Results}

In the absence of subsidies and direct financial incentives to employers or supportive legislation, employers are the ones who largely moderate what will happen to workplace wellbeing programs or/and older employees in the workplace. That is why the first activity within the ePlatform is the campaign aimed at a company's management. In the first wave, we included 31 companies out of the planned 80, represented by 74 employees in different managerial positions.

The campaign for company managers consists of nine e-mails, that recipients receive weekly. In case of their unresponsiveness (unread message), the user automatically receives an encouragement message with a reminder. The entire campaign lasts 56 days. The contents of the campaign follows the steps to the successful implementation of the workplace wellbeing program in the company: (1) presentation of steps in the process of establishing the workplace wellbeing program, (2) implementation of a screening questionnaire on the health of the company/employees, (3) identification of necessary measures 
and good practices through the analysis of the screening questionnaire and introduction with the STAR-VITAL Wiki page (repository of $150+$ known occupational health promotion and workplace wellbeing measures), (4) elaboration or supplementation of the existing health promotion plan, ( 5 and 6 ) adaptation of already implemented measures, (7) introduction of change management and (8) a system for monitoring the quality of the implementation of the workplace wellbeing in the company. In the last step (9), we encourage the company to celebrate the achieved goals on an ongoing basis.

The success rate of the campaign for the management at the time of writing (March 2020) reached $82 \%$ (23 active companies out of 28 ), while the latest results (July 2020) show a 68\% (21 active companies out of 31). The current average share of read e-mail content in the campaign for managers is $60 \%$. All STAR-VITAL measures are being evaluated by participants, ePlatform content including. In ePlatform users numerically evaluate the content on a scale from 5 (highest score) to 1 . The current satisfaction rating of the received content for the managers is 4.5 . It also needs to be mentioned that so far 25 companies or 869 employees have completed the screening questionnaire. We have already included many of them in campaigns in the field of physical activity and ergonomics, nutrition and stress.

\section{Discussion}

In the STAR-VITAL project, we encourage stakeholders (companies and employees) to actively promote occupational health and wellbeing through various channels. The greatest potential for constant communication and user promotion is the ePlatform, which our analysis also confirms. The results indicate a high share of user (company) activity, satisfaction with received content and a satisfactory level of content readability. Campaign performance varies in time (holiday leaves and events when emails are treated as SPAM). The situation related to COVID-19 also proved to be an important factor, pushing a significant part of companies to face the challenges of stopping their operations and production, which consequently meant a stalemate in workplace wellbeing activities.

Factors important for the successful introduction and implementation of occupational/workplace health promotion and wellbeing, have already been explored by numerous authors (Archer, 2012; Bakker, 2015; Spence, 2015; Schmid et al., 2017; Santos, 2019). In the STAR-VITAL project, based on the richness of data monitored by the ePlatform (CRM system), we will upgrade these studies and determine whether the readiness and level of active participation of stakeholders (employees, companies) are also influenced by other, less researched factors: line of business, management support in the implementation of health promotion, company specifics, demographic characteristics, personal values of health promoters and company management, awareness of expected benefits, perceived level of (health) problems in employees or personnel problems in the 
company, etc. Analysis of variance and later also multilevel modelling will be used for the analysis.

\section{Conclusions}

Regardless of the fact that many activities in the field of workplace wellbeing are currently being carried out in Slovenia, their introduction and implementation in a practical environment is still a challenge. With the proper use of the ePlatform, we are on the way to provide greater support and empowerment for both employees and companies to change their behaviour at work (and outside work), which leads to greater care for their own health and prolongation of work activity. To make the impact even better, it is necessary to identify the approaches, activities and/or factors that motivate those involved to participate and change behaviour.

\section{References}

Archer S., 2012. Health is wealth: The rise of workplace wellness. IDEA Fitness Journal, vol. 9, pp. 38-44.

Bakker A. B., 2015. Towards a multilevel approach of employee wellbeing. European Journal of Work and Organizational Psychology, vol. 24, pp. 839843. Available from: 10.1080/1359432X.2015.1071423

Bal A.C., Reiss A.E., Rudolph C.W and Baltes B.B, 2011. Examining positive and negative perceptions of older workers: a meta-analysis. The Journals of Gerontology, Series B: Psychological Sciences and Social Sciences, vol. 66, pp. 687-698.

Emily S., 2019. "Introducing the Workplace Well-Being Program Implementation Model: A Model to Inform the Establishment of Organizational Well-Being Programs". Master of Applied Positive Psychology (MAPP) Capstone Projects. Available from: 163.https://repository.upenn.edu/ mapp_capstone/163

ePrvak d.o.o., 2020. Kako vam marketing automation prihrani čas in izboljša prodajo? [viewed 6 July 2020]. Available from: https://www.eprvak.si/ marketing-automation/

Juneja P., 2020. Management Study Guide. Customer Relationship Management - What is CRM? [viewed 6 July 2020]. Available from: https://www. managementstudyguide.com/what-is-crm.htm

Loeppke R.R., Schill L.A., Chosewood L.C., Grosch J.W., Allweiss P. and Burton W.N. et al., 2013. Advancing workplace health protection and promotion for an aging workforce. Journal of Occupational and Environmental Medicine, vol. 55, no. 5, pp. 500-506.

Schmid J. A., Jarczok,M. N., Sonntag,D., Herr,R. M., Fischer J. E. and Schmidt B, 2017. Associations between supportive leadership behavior and the costs of absenteeism and presenteeism: An epidemiological and econom- 
ic approach. Journal of Occupational and Environmental Medicine, vol. 59, pp. 141-147.

Spence G. B., 2015. Workplace wellbeing programs: If you build it they may NOT come ... because it's not what they really need! International Journal of Wellbeing, vol. 5, pp. 109-124. Available from: 10.5502/ijw.v5i2.7

STAR-VITAL, 2020. O projektu. [viewed 3 July 2020]. Available from: https:// www.star-vital.si/o-projektu

World Health Organization, 2020. Healthy workplaces: a WHO global model for action. Five Keys to Healthy Workplaces. [viewed 3 July 2020]. Available from: https://www.who.int/occupational_health/5_keys_EN_web. pdf?ua $=1$ 